\title{
A IMPLEMENTAÇÃO DAS AUTARQUIAS EM ANGOLA COMO ALAVANCA PARA A RESOLUÇÃO DE PROBLEMAS LOCAIS ${ }^{1}$
}

\author{
THE IMPLEMENTATION OF AUTHORITIES IN ANGOLA AS \\ A LEVERAGE FOR LOCAL PROBLEMS
}

Clarice Chinofila Beu²

\begin{abstract}
Resumo
Este trabalho tem por objetivo demonstrar os benefícios que a implementação do sistema autárquico trará para o país. O tema em causa é um dos assuntos mais debatidos actualmente tendo em conta a situação actual que o país vive (crise económica e financeira). Porém, embora haja divulgação (tímida), nota-se que a maior parte da população ainda carece de esclarecimentos quanto aos benefícios que o referido sistema poderá trazer para as comunidades. Para a elaboração desta pesquisa científica, baseamo-nos na pesquisa exploratória de modos a obtermos maiores informações sobre o assunto em causa. Ao longo da pesquisa analisa-se a questão da centralização e descentralização da administração pública no país, da autonomia que as localidades terão para a melhoria da qualidade de vida da população e, por fim, fez-se uma abordagem a respeito dos benefícios que as autarquias trarão após a sua implementação.
\end{abstract}

Palavras-chave: Autarquias Locais. Centralização. Descentralização. Autonomia Local.

\begin{abstract}
This work aims to demonstrate the benefits that the implementation of the autarchic system will bring to the country. The subject at stake is one of the most currently debated essues taking to accorent the current situation in the country (economic and financial crisis). However, although there is a diffusion (timid), it is noticed that the majority of population still needs clarification to the benefit that the afore-mentioned system can bring to the communities. For the elaboration of this scientific research, we base ourselves on the exploratory research of manners to obtain more information on the subject at stake. Throughout the research, we analyze the centralization and decentralization of public administration in the country, the autonomy that localities will have for the quality improvement of life of the population's life, and, finally, an approach was made on the benefits that the Authorities will bring after its implementation.
\end{abstract}

Keywords: Local Authorities. Centralization. Decentralization. Local Autonomy.

1 Artigo submetido em 30/03/2017 pareceres de análise em 10/04/2017, 18/04/2017 e 13/12/2017 aprovação comunicada em 15/12/2017.

2 Mestranda em Administração e Desenvolvimento Local, na Faculdade de Economia da Universidade 11 de Novembro em Cabinda, Angola. E-mail: <claricechbeu@hotmail.com> 
Sumário: 1. Introdução. 2. As Autarquias Locais. 2.1. Centralização e descentralização administrativa. 2.2. O princípio da autonomia local. 3. Benefícios da Implementação das Autarquias. 3.1. Desafios das autarquias locais para Angola. 4. Considerações Finais. 5. Referências.

\section{INTRODUÇÃO}

O presente trabalho científico sobre a implementação das autarquias em Angola como alavanca para a resolução de problemas locais é um tema que nos desperta bastante interesse uma vez que grande parte da população não tem conhecimento sobre as autarquias muito menos das vantagens e/ou benefícios que a implementação da mesma trará para as localidades. É neste sentido que queremos contribuir com este trabalho demostrando os benefícios que a implementação das autarquias trará se forem implementados no nosso país visto que para promover o desenvolvimento local é necessário implementar acções que permitam a activa participação da população da localidade em causa.

Não queremos com isso dizer que com este sistema todos os problemas vividos pelas comunidades serão ultrapassados, mas que com a implementação das autarquias os problemas básicos enfrentados pelas comunidades serão resolvidos com a intervenção dos munícipes sendo estes os conhecedores dos problemas pois o enfrentam diariamente, e melhor do que ninguém conhecem quais as prioridades na resolução. Para tal propusemo-nos a estudar como as autarquias irão contribuir na resolução dos problemas enfrentados pelas comunidades. A fim de alcançar os propósitos desejados, utiliza-se a pesquisa exploratória na presente pesquisa de modos a obtermos maiores informações sobre o assunto em causa e por se tratar de um assunto que ainda carece de estudos.

Para a finalidade exposta, analisa-se a questão da centralização e descentralização da administração pública, da autonomia que as localidades terão para o exercício das suas funções e por fim, faz-se uma abordagem dos benefícios que as autarquias trarão sendo que elas estabelecem um mecanismo essencial na descentralização do poder e contribuem para o desenvolvimento de qualquer país se criadas as condições necessárias para sua efectiva implementação. É importante realçar que para o real funcionamento das autarquias, para que elas contribuam de 
forma eficaz, as condições têm que estar preparadas para então haver eleições autárquicas.

\section{2}

\section{AS AUTARQUIAS LOCAIS}

Os problemas fundamentais da governação local em Angola continuam a ser os mesmos (deficiente saneamento básico, deficiente distribuição da água, energia eléctrica, falta de iluminação pública, melhoramento das vias de comunicação e acesso, ordenamento do território, saúde, educação, cultura, ambiente, desemprego e outros) e as autarquias podem ser o caminho para a sua solução. É importante referir que a anterior Lei Constitucional já fazia referência das autarquias locais no artigo $146^{\circ}$, definindo-se como pessoas colectivas territoriais que visam a prossecução de interesses próprios das populações, dispondo para o efeito de órgão representativos elitos e de liberdade de administração das respectivas colectividades.

Nos termos da Constituição de 2010, as autarquias locais são pessoas colectivas territoriais correspondentes ao conjunto de residentes em certas circunscrições do território nacional e que asseguram a prossecução de interesses específicos resultantes da vizinhança, mediante órgãos próprios representativos das respectivas populações ${ }^{3}$.

Segundo a mesma Constituição, as atribuições das autarquias vão desde o domínio da educação, saúde, energias, águas, equipamento rural e urbano, património, cultura e ciência, transportes e comunicações, tempos livre e desporto, habitação, acção social, protecção civil, ambiente e saneamento básico, defesa do consumidor, promoção do desenvolvimento económico e social, ordenamento do território, polícia municipal, cooperação descentralizada e geminação (artigo. $219^{\circ}$ ). As autarquias dispõem ainda de recursos financeiros proveniente do Orçamento Geral do Estado (artigo. $104^{\circ}, 2$ ) e de rendimentos e impostos locais (artigo. $215^{\circ}$ ) e gozam ainda de autonomia e dispõem de poder regulamentar próprio, nos termos da lei (artigo. $214^{\circ}$ ).

Para o exercício dessas tarefas e/ou missões, os órgãos autárquicos estruturar-se-ão em assembleia representativa com poderes deliberativos, 
composta por representantes locais, eleitos por sufrágio universal, igual, livre e directo; o executivo colegial com um presidente e secretários responsáveis pelos vários pelouros, nomeados pelo presidente do executivo municipal, sendo todos eles responsáveis perante a assembleia representativa. A semelhança do que acontece com o executivo central e nos termos do artigo $220^{\circ}$, n. ${ }^{\circ} 4$ da Constituição da República de Angola, o presidente do órgão executivo da autarquia é o cabeça da lista mais votada para a assembleia. (TEIXEIRA, 2013).

É importante realçar que as autarquias locais são pessoas destintas do Estado. "Elas não fazem parte do Estado, não são o Estado, não pertencem ao Estado. São entidades independentes e completamente destintas do Estado embora possam por ele ser fiscalizadas, controladas ou subsidiadas" (AMARAL, 2006, p. 481). Embora as autarquias não sejam instrumentos de acção do Estado mas formas independentes de organização das populações locais, elas são de fundamental importância para o Estado contribuindo não só no campo administrativo, mas em todos os ramos da função pública.

Para a resolução dos problemas que as comunidades enfrentam surge a necessidade urgente de implementação das autarquias. Constacta-se hoje, muita morosidade no que tange a resolução de problemas básicos sobretudo nas aldeias, pois na exposição de um simples problema ao administrador, este por insuficiência de poder para resolver envia para o administrador municipal que por sua vez envia para seus superiores. A mesma morosidade podemos constactar em diversos sectores da administração pública, no tratamento de documentos legais como o Bilhete de Identidade e o Passaporte por exemplo. Muitos desses serviços podem levar no mínimo cinco meses para a sua emissão devido a dependência dos serviços centrais. É necessário implementar as autarquias em todo país para que haja descentralização do poder e maior fluidez dos serviços. Esta descentralização trará consigo muitas melhorias não só no que tange ao funcionamento dos serviços prestados pelas instituições públicas mas permitirá também a participação da população nas questões económicas e políticas, haverá uma melhor distribuição dos bens e serviços, melhor liberdade de expressão, entre outros.

A implementação das autarquias é um imperativo constitucional que não pode ser ignorado mesmo se uma norma transitória dispõe que "a institucionalização efectiva das autarquias locais obedece ao princípio do gradualismo" (artigo. 24204),

4 Conforme o artigo $242^{\circ}$ da Constituição de Angola, a institucionalização efectiva das autarquias locais obedece ao princípio do gradualismo. Os órgãos competentes do Estado determinam por lei 
princípio admitido a partir do momento da publicação da Constituição de 2010. Dada as condições actuais, numa primeira instância acredito que não serão todas as localidades que terão essa entidade administrativa mas gradualmente alguns podem passar para as autarquias locais e, nos anos subsequentes outros, após se criar condições em determinadas localidades. Para uma maior aproximação dos serviços a população, precisa-se da materialização das autarquias locais.

\subsection{Centralização e descentralização administrativa}

A administração pública é organizada de forma hierárquica, em cujo cimo está o Chefe do Poder Executivo. A actividade administrativa pode ser prestada de duas formas: centralizada, onde o serviço é prestado pela administração directa, e a descentralizada, em que a prestação é deslocada para outras Pessoas Jurídicas (MELLO, 2000, p. 126). As actividades administrativas até aqui prestadas são vistas como instituições detentoras de poder e autoridade e não como instituições detentoras de deveres ou de obrigações de estado. Podemos então questionar o seguinte: quais são as administrações que reconhecem que o serviço público é uma obrigação do Estado para com o cidadão? $\mathrm{Na}$ nossa óptica as atribuições administrativas são concedidas aos vários órgãos que compõem a hierarquia, criando-se uma relação de coordenação e subordinação entre uns e outros. Isso é feito para descongestionar, desconcentrar, tirar do centro um volume grande de atribuições, para permitir seu mais adequado e racional desempenho.

Segundo Amaral (1994), a "centralização"5 e a descentralização têm a ver com a unicidade ou pluralidade de pessoas colectivas públicas. A descentralização supõe a existência de, pelo menos, duas pessoas, entre as quais se repartem as competências.

A descentralização implica a acumulação e partilha de poderes do governo central com o governo local. Pode definir-se a descentralização em dois planos: No plano jurídico, diz-se que é o sistema em que a função administrativa está confiada

a oportunidade da sua criação, o alargamento gradual das suas atribuições, o doseamento da tutela de mérito e a transitoriedade entre a administração local do Estado e as autarquias locais.

5 Segundo Amaral (1994), existe centralização no plano político-administrativo quando os órgãos das autarquias locais são livremente nomeados e demitidos pelos órgãos do Estado, quando devem obediência ao Governo ou ao partido único, ou quando se concentrem sujeitos a formas particularmente intensas de tutela administrativa, designadamente a uma ampla tutela de mérito. 
não apenas ao Estado, mas também a outras pessoas colectivas territoriais, designadamente as autarquias locais. No plano político-administrativo, diz-se que há descentralização quando os órgãos das autarquias locais são livremente eleitos pelas respectivas populações, quando a lei os considera independentes na órbita das suas atribuições e competências, e quando estiverem sujeitos a formas atenuadas de tutela administrativa, em regra restritas ao controlo da legalidade. (AMARAL, 1994 apud BENVINDO, 2012, p. 38).

Diz-se centralizado, o sistema em que todas as atribuições administrativas de um dado país são por lei conferidas ao Estado, não existindo, portanto, quaisquer outras pessoas colectivas públicas incumbidas do Exercício da função administrativa. Segundo a Constituição de 2010, Angola é um Estado unitário descentralizado, como podemos constatar no artigo $8^{\circ}$ da referida Constituição.

Importa destacar três formas de descentralização segundo Luciano Benvindo (2012):

a) Territorial que dá origem à existência de autarquias locais;

b) Associativas que dá origem as associações públicas e;

c) Institucional a que dá autonomia aos institutos públicos e as empresas públicas. Quanto a descentralização territorial, apesar de estar prevista não está ainda implementada em Angola as autarquias locais o que nos leva a reflectir sobre a existência ou não existência de descentralização territorial. (AMARAL, 1994 apud BENVINDO, 2012).

"A existência legal das autarquias locais, e o reconhecimento da sua autonomia face ao poder central, fazem parte da própria essência da democracia, e traduzem-se no conceito jurídico-político de descentralização" (AMARAL, 2006).

Onde quer que haja autarquias locais, enquanto pessoas colectivas distintas do Estado, e dele juridicamente separados, poderá dizer-se que há descentralização. O que significa que as tarefas da administração pública não são desempenhadas apenas por uma só pessoa, o Estado, mas também por várias pessoas colectivas diferentes, encarregados por lei de exercer actividade administrativa. Pode no entanto haver descentralização em sentido jurídico e não haver descentralização em sentido político, e sobre a aparência de descentralização haver um regime fortemente centralizado. Quando além da descentralização em sentido jurídico há descentralização em sentido político, os órgãos representativos das populações locais são eleitos livremente por estes. 
É importante frisar, que para haver um desenvolvimento justo e democrático em Angola, é necessário haver descentralização pois pensamos que é um dos grandes desafios de Angola: o de construir um estado democrático íntegro e eficiente. Estamos a falar de um processo político que visa transferir atribuições das administrações central do Estado para outras entidades territorialmente delimitadas. Pela descentralização rompe-se uma unidade personalizada e não há vínculo hierárquico entre a Administração Central e a pessoa estatal descentralizada. Assim a segunda não é subordinada à primeira. Entretanto, a descentralização deve ser vista como um meio para a administração melhor servir a causa do desenvolvimento de Angola que todos idealizamos e merecemos. As exigências deste modelo organizacional não nos colocam só desafios de natureza infraestrutural, mas a preparação humana que vai servir os órgãos locais autárquicos. Neste sentido, vários esforços têm sido feito no âmbito da formação, para a especialização do capital humano de modos a servir melhor a comunidade.

Penso que é hora de fazer compreender sobre o processo administrativo, judicial e político pois a descentralização é um elemento fundamental para formalização do modelo político do país que se pretende. É necessário que a população saiba desde já os princípios orientadores de todo o processo: como o processo irá acontecer, se os governadores serão eleitos ou nomeados, que poderes terão os municípios, quais as atribuições que os municípios terão, que poderes de decisão e quais os princípios fundamentais. Acreditamos que se houver descentralização os serviços chegarão com maior eficiência e eficácia a população. Pese embora a nossa Constituição prevê a descentralização o importante é pensar no que realmente se pretende com o processo e como deve-se materializar sendo que a descentralização contribui na efectiva produção da democracia que se traduz sobretudo na liberdade de expressão e consequentemente na melhoria da qualidade de vida da população. Sendo que a existência legal das autarquias locais, e o reconhecimento da sua autonomia face ao poder central, fazem parte da própria essência da democracia, estamos em condições de abordar a respeito deste importante elemento "autonomia local" que é um dos princípios previstos na Constituição angolana. 


\title{
2.2 O princípio da autonomia local
}

O princípio da autonomia local é reconhecido pela legislação interna ou seja pela Constituição conforme referenciado anteriormente. Segundo a Constituição angolana, a autonomia local compreende o direito e a capacidade efectiva de as autarquias locais gerirem e regulamentarem, nos termos da Constituição e da lei, sob sua responsabilidade e no interesse das respectivas populações, os assuntos públicos locais (Artigo 214..$^{\circ}$ ) . O entendimento do sentido e alcance deste princípio tem variado ao longo dos tempos, conforme os regimes políticos, e na actualidade não há unanimidade de opiniões acerca do assunto (AMARAL, 2006). No liberalismo, a autonomia local constituía um refúgio próprio das autarquias face ao Estado. Hoje, em pleno Estado dominado pelo avanço tecnológico o princípio da autonomia local não pode ser entendido da mesma maneira.

\begin{abstract}
Dantes, o que era de interesse nacional competia ao Estado; o que era de interesse local competia às autarquias locais; mas, hoje em dia, quase tudo que é local tem de ser enquadrado numa política pública definida a nível nacional como é o caso do ambiente, ordenamento do território, urbanismo, fomento turístico, etc.; por outro lado, e inversamente, todas as políticas nacionais têm uma dimensão regional e diversificada, exigindo adaptações, especialidades, respeito pelas particularidades de cada área ou localidade. Daí que muitos autores pretendam escusar da autonomia local e substituir o conceito, ou reconvertê-lo, de modo a assegurar sobretudo o direito de as autarquias locais participarem na definição das grandes orientações nacionais (leis, políticas públicas, planeamento), assim como na respectiva execução. A autonomia local seria, agora, solidariedade das autarquias com o Estado, participação, colaboração. De uma autonomia-liberdade ter-se-ia passado, ou estaria a passar-se, para uma autonomia-participativa. Esta concepção não é aceitável pelo autor, pelo menos nas suas modalidades mais radicais. (AMARAL, 2006).
\end{abstract}

A autonomia local é um espaço de livre decisão das autarquias sobre assuntos do seu interesse próprio. O princípio da autonomia local compreende a ideia de participação da população exigindo nomeadamente poderes de decisões independentes e o direito de recusar soluções impostas pelo poder central. As autarquias locais têm completa liberdade de iniciativa relativamente a qualquer questão que não seja excluída da sua competência ou atribuída a uma outra autoridade, desde que esteja dentro dos limites da lei. Ela tem o direito de decisão por isso não subordina a outrem. O exercício das responsabilidades públicas deve 
pertencer às autoridades mais próximas do cidadão de formas a resolver as questões ligadas a população. Assim, segundo Amaral (2006), o princípio da autonomia local pressupõe e exige, pelo menos, os seguintes direitos:

a) $\mathrm{O}$ direito e a capacidade efectiva de as autarquias regulamentarem e gerirem, nos termos da lei, sob sua responsabilidade e no interesse das respectivas populações, uma parte importante dos assuntos públicos;

b) o direito de participarem na definição das políticas públicas nacionais que afectam os interesses próprios das respectivas populações;

c) o direito de partilharem com o Estado ou com a região as decisões sobre matérias de interesse comum;

d) o direito de, sempre que possível, regulamentarem a aplicação das normas ou planos nacionais por forma a adaptá-los convenientemente as realidades locais.

Quanto aos recursos financeiros, o artigo $215 .^{\circ}$ da tão citada Constituição diz que devem ser proporcionais às atribuições previstas pela Constituição ou por lei, bem como aos programas de desenvolvimento aprovados. A lei estabelece que uma parte dos recursos financeiros das autarquias locais deve ser proveniente de rendimentos e impostos locais. Esses recursos permitirão as autarquias locais dispor livremente o exercício das suas atribuições, e os sistemas financeiros nos quais se baseiam os recursos de que dispõem as mesmas, devem ser de natureza suficientemente diversificada e evolutiva de modo a permitir-Ihes seguir, tanto quanto possível na prática, a evolução real dos custos do exercício das suas atribuições.

Pode-se com isso perceber que a autonomia que as comunidades/municípios terão é um dos benefícios que as autarquias trarão após a sua implementação no nosso país pelo acima exposto, pois todas as acções em prol da mesma estarão ligadas para o bem-estar da população sendo ela o alvo de todo o processo de desenvolvimento. Com o Desenvolvimento Local se busca a melhoria de qualidade de vida das comunidades e a maior participação destas nas definições do poder político, em favor de um ambiente saudável e socialmente justo, para as gerações actuais e futuras.

\section{BENEFÍCIOS DA IMPLEMENTAÇÃO DAS AUTARQUIAS}

O desenvolvimento local é um tema muito debatido actualmente pelo facto de ser um processo contínuo, visando a construção de caminhos que perspectivam 
a projecção futura de uma dada comunidade a um patamar melhor e com impactos visíveis sobre a população e o meio. Apraz-nos dizer que para promover o desenvolvimento local é necessário implementar acções que permitam a activa participação da população da localidade em causa. Entendemos nós que as autarquias proporcionam esse caminho que visa a melhoria da qualidade de vida da população. Apesar das autarquias constituírem uma alavanca para a resolução dos problemas básicos da população como o saneamento, educação, saúde, urbanização e outros, importa referir que elas, não irão a priori resolver todos os problemas enfrentados pelas comunidades mas certamente uma boa parte dos problemas serão resolvidos.

Dentre os vários benefícios que a implementação das autarquias trará, podemos referenciar os seguintes:

1) Consolidação da democracia que assenta sobretudo na liberdade de expressão e na oportunidade de melhorar a qualidade de vida da população;

2) A participação da população na tomada de decisões públicas em assuntos ligados aos seus interesses. A participação da comunidade é um dos objectivos do Estado moderno apesar de que a população já participa na gestão pública de um ou outro jeito.

3) A implementação das autarquias irá permitir utilizar melhor o sentimento das populações locais relativamente aos seus problemas, e facilitará a mobilização das iniciativas e das potências locais para as tarefas da administração pública para a realização do bem-estar comum;

4) Irá garantir o acesso da população aos serviços básicos como: a água, o saneamento, a energia eléctrica, a iluminação pública, melhoramento das vias de comunicação e acesso, ordenamento do território, saúde, educação, cultura, ambiente, desporto e outros aspectos de interesse das comunidades locais.

\subsection{Desafios das autarquias locais para Angola}

São vários os desafios que poderíamos apontar neste ponto para as autarquias em Angola. No entanto, gostaríamos de frisar alguns e os mais urgentes ao nosso ver para atingirmos o bem-estar comum. Um dos grandes desafios das autarquias locais em Angola é proporcionar a efectiva descentralização 
administrativa pois ela permitirá liberdades locais. Conforme referimos no ponto que aborda sobre centralização e descentralização administrativa, Angola segundo a sua Constituição é um Estado unitário descentralizado. Por que insistir na questão da descentralização administrativa? Na verdade o que se pretende, é que as comunidades vivam e sintam essa descentralização.

\begin{abstract}
A descentralização promove a mobilização de recursos locais fornecendo um melhor sistema de coordenação, supervisão, controlo e execução dos projectos e implicando um envolvimento directo das populações na prossecução dos objectivos de desenvolvimento. Uma efectiva descentralização contribui, pois, para a manutenção da estabilidade política e da união nacional e, consequentemente para o desenvolvimento, através da promoção de uma melhor representação de todos os grupos sociais na satisfação das suas necessidades, contribuindo para uma maior equidade na alocação dos recursos governamentais e na redução das tensões sociais. Por último a descentralização permite aos cidadãos participarem activamente nas decisões políticas públicas. (SAWADOGO, 2001 apud BENVINDO, 2012).
\end{abstract}

Outro grande desafio das autarquias é garantir a população o acesso aos serviços básicos como: a água, o saneamento, a energia eléctrica, a iluminação pública, o melhoramento das vias de comunicação e acesso, ordenamento do território, saúde, educação, cultura, ambiente, desporto, desemprego e o combate a pobreza. Falando deste último, o conflito armado e as suas consequências directas e indirectas são apontadas como as causas principais para o elevado índice de pobreza que caracteriza a população angolana. O processo de destruição em que este país esteve envolvido foi demasiado longo e abrangente. Para além das infraestruturas físicas foram igualmente destruídos os modos de vida, culturas e identidades, resultando daí uma sociedade dividida. Todos os problemas acima referenciados são apontados como efeitos do longo período de conflito armado que o país atravessou.

O fim do conflito armado tem possibilitado uma melhor definição das estratégias para a erradicação da pobreza bem como a análise dos modos de vida das comunidades mais vulneráveis a condições de pobreza. Segundo Oliveira (2012), a investigação sobre os modos de vida das categorias sociais mais vulneráveis às condições de pobreza, permitiu identificar cinco modos de vida da pobreza em Angola: restrição, destruição, transitoriedade, investimento na mobilidade e desafectação. 
O modo de vida da restrição, caracterizado pela precariedade e instabilidade no emprego distingue-se da destruição (nível de vida nos limites de sobrevivência) pelo acesso ao mercado de trabalho. A transitoriedade é característica dos desempregados, famílias monoparentais, alguns reformados e jovens à procura do primeiro emprego. Os poucos que conseguem criar alguma estabilidade investem tudo o que têm na educação dos filhos, para que esta segunda geração saia da condição da pobreza. Esse investimento na mobilidade social é feito por alguns operários e empregados com alguma escolaridade e rendimento fixo. O último modo de vida identificado é o da desafectação, que é característico de toxicodependentes, reclusos e ex-reclusos, crianças de rua e sem abrigo. Categorias sociais que rompem os laços com a sociedade.

Esses e outros factores estão na base da luta do governo hoje para a mudança do quadro da pobreza e melhoria das condições de vida da população. Neste sentido, vários estudos têm sido feito para resolver primeiramente os problemas básicos que a população enfrenta. A intenção de implementação das autarquias locais é um dos passos rumo a este fim.

A redução das assimetrias regionais e a desigualdade social é outro desafio das autarquias locais. Um dos factores que está na base dessas diferenças é a guerra. Durante esse período, grande parte da população rural sentiu a necessidade de abandonar sua terra a procura de segurança nos centros urbanos e começou a desenvolver uma série de actividades diferente ao que realmente sabia fazer (como a produção agrícola de subsistência) e passaram a realizar trabalhos como venda em mercados paralelos e outros tipos de actividades de modos a melhorarem a sua condição de vida. O número de pessoas que teve de abandonar seus lares nas zonas rurais e passaram a viver nos centros urbanos, principalmente na capital do país e capitais das demais províncias é elevado. Esse crescimento da população nos centros urbanos não foi acompanhado pela administração o que levou a um crescimento desordenado da população nas periferias trazendo consigo muitos problemas como a falta de urbanização, actualmente um dos grandes problemas enfrentado pelas comunidades. Essa transição da população rural para os centros urbanos levou ao crescimento de algumas regiões e estagnação de outras e consequentemente a desigualdade social.

Hoje há uma grande preocupação em saber como vivem as populações locais. Com a implementação das autarquias e concomitantemente a descentralização visível, será possível construir o país que todos nós gostaríamos de ter: com mais justiça e igualdade. Cada citadino irá participar com a livre opinião sem ter receio de falar o que não vai bem, pois as autarquias permitem a 
participação próxima e activa da população no que diz respeito as questões da sua localidade.

\section{CONSIDERAÇÕES FINAIS}

Com base nas reflexões feitas neste artigo chegamos as seguintes conclusões:

Para uma maior aproximação dos serviços a população, é importante que se implemente as autarquias locais ainda que de forma gradual, princípio admitido a partir do momento da publicação da Constituição de 2010. Dada as condições actuais, numa primeira instância acreditamos que não serão todas as localidades que terão essa entidade administrativa mas gradualmente alguns podem passar para as autarquias locais e, os outros posteriormente, após se criar condições em determinadas localidades;

A materialização das autarquias em Angola, é um imperativo incondicional para que haja descentralização do poder e maior fluidez dos serviços. Esta descentralização trará consigo muitas melhorias não só no que tange ao funcionamento dos serviços prestados pelas instituições públicas mas permitirá também a participação da população nas questões económicas e políticas, haverá uma melhor distribuição dos bens e serviços, melhor liberdade de expressão, entre outros;

As actividades administrativas até aqui prestadas são vistas como instituições detentoras de poder e autoridade e não como instituições detentoras de deveres ou de obrigações de estado. Podemos então questionar o seguinte: quais são as administrações que reconhecem que o serviço público é uma obrigação do Estado para com o cidadão? Na nossa óptica as atribuições administrativas são concedidas aos vários órgãos que compõem a hierarquia, criando-se uma relação de coordenação e subordinação entre uns e outros. A descentralização implica a partilha de poderes do governo central com o governo local; o que significa que as tarefas da administração pública não são desempenhadas apenas por uma só pessoa, o Estado, mas também por várias pessoas colectivas diferentes, encarregados por lei de exercer actividade administrativa; 
É importante frisar, que para haver um desenvolvimento justo e democrático em Angola, é necessário haver descentralização pois pensamos que é um dos grandes desafios de Angola: construir um estado democrático íntegro e eficiente. Entretanto, a descentralização deve ser vista como um meio para a administração melhor servir a causa do desenvolvimento de Angola pois com ela, os serviços chegarão com maior eficiência e eficácia a população.

O princípio da autonomia local compreende a ideia de participação da população exigindo nomeadamente poderes de decisões independentes e o direito de recusar soluções impostas pelo poder central. Assim, as autarquias locais têm completa liberdade de iniciativa relativamente a qualquer questão que não seja excluída da sua competência ou atribuída a uma outra autoridade, desde que esteja dentro dos limites da lei;

Apesar das autarquias constituírem uma alavanca para a resolução dos problemas da população como a água, o saneamento, a energia eléctrica, a iluminação pública, o melhoramento das vias de comunicação e acesso, a urbanização, saúde, educação, cultura, ambiente, desporto, desemprego e a pobreza e outros, importa referir que elas, não irão a priori resolver todos os problemas enfrentados pelas comunidades mas certamente uma boa parte dos problemas serão resolvidos. Um dos grandes desafios das autarquias é garantir a população o acesso aos serviços básicos.

A redução das assimetrias regionais e a desigualdade social é outro desafio das autarquias locais. Todo esforço em prol da implementação das autarquias locais é para promover o desenvolvimento das localidades. Com o desenvolvimento local se busca a melhoria de qualidade de vida das comunidades e a maior participação destas nas definições do poder político, em favor de um ambiente saudável e socialmente justo, para as gerações actuais e futuras.

\section{5 \\ REFERÊNCIAS}

AMARAL, Diogo Freitas do. Curso de Direito Administrativo. 2. ed., Volume I, Lisboa: Edições Almeida, 1994.

AMARAL, Diogo Freitas do. Curso de Direito Administrativo. 3. ed., $2^{\mathrm{a}}$. reimp. Lisboa: Edições Almedina, 2006. 
TEIXEIRA, Carlos. Colectânea Universidade e Cidade, U\&C - Educação, Sociedade e Estado. Editora Capatê-Publicações, Ltda, 2013.

Constituição da República de Angola (2010). Luanda: Editora Imprensa Nacional, 2010.

DI PIETRO, Maria Sylvia Zanella. Direito Administrativo. 23. ed. São Paulo: Atlas, 2010.

BENVINDO, Luciano. Descentralização e Desconcentração na Administração Pública em Angola. Lisboa: Escolar, 2012.

MELLO, Celso António Bandeira de. Curso de Direito Administrativo. 12. ed. São Paulo: Malheiros, 2000. 